\title{
Pharmacotherapy for post-traumatic stress disorder: systematic review and meta-analysis
}

Mathew Hoskins, Jennifer Pearce, Andrew Bethell, Liliya Dankova, Corrado Barbui, Wietse A. Tol, Mark van Ommeren, Joop de Jong, Soraya Seedat, Hanhui Chen and Jonathan I. Bisson

\section{Background}

Pharmacological treatment is widely used for post-traumatic stress disorder (PTSD) despite questions over its efficacy.

\begin{abstract}
Aims
To determine the efficacy of all types of pharmacotherapy, as monotherapy, in reducing symptoms of PTSD, and to assess acceptability.
\end{abstract}

\section{Method}

A systematic review and meta-analysis of randomised controlled trials was undertaken; 51 studies were included.

\section{Results}

Selective serotonin reuptake inhibitors were found to be statistically superior to placebo in reduction of PTSD symptoms but the effect size was small (standardised mean difference $-0.23,95 \% \mathrm{Cl}-0.33$ to -0.12 ). For individual pharmacological agents compared with placebo in two or more trials, we found small statistically significant evidence of efficacy for fluoxetine, paroxetine and venlafaxine.

\section{Conclusions}

Some drugs have a small positive impact on PTSD symptoms and are acceptable. Fluoxetine, paroxetine and venlafaxine may be considered as potential treatments for the disorder. For most drugs there is inadequate evidence regarding efficacy for PTSD, pointing to the need for more research in this area.

\section{Declaration of interest}

None.
Post-traumatic stress disorder (PTSD) is a common mental disorder with an estimated prevalence of $15.4 \%$ in the most robust epidemiological studies (those using diagnostic interviews and random samples) of conflict-affected populations, ${ }^{1}$ and a 12 -month prevalence across the world of $3-4 \% .^{2}$ The disorder may occur in people of any age who have been exposed to one or more exceptionally threatening or horrifying events. Characteristic symptoms include re-experiencing, avoidance and hyperarousal., The disorder is associated with substantial comorbidity, such as depression, anxiety and substance misuse, ${ }^{5}$ and significant economic burden. ${ }^{6}$ Previous meta-analyses of pharmacological treatment of PTSD have been inconsistent. The UK's National Institute for Health and Care Excellence (NICE) guidelines found that only paroxetine, mirtazapine, amitriptyline and phenelzine were significantly superior to placebo. ${ }^{7}$ Owing to the relatively small effect sizes and sample sizes, none of these drugs was included as a first-line treatment for PTSD; all were recommended as second-line treatment after the initiation of trauma-focused psychological treatment. The guidelines of the Australian Centre for Posttraumatic Mental Health (ACPMH), consistent with NICE, recommended that pharmacological interventions should not be used in preference to trauma-focused psychological treatment. ${ }^{8}$ Other reviews have been more positive about pharmacological treatment, grouping selective serotonin reuptake inhibitors (SSRIs) together and rating them as equivalent to trauma-focused psychological treatments. ${ }^{9,10}$ A Cochrane review reported strong benefits, ${ }^{11}$ but the Institute of Medicine found inadequate evidence to determine the efficacy of pharmacological treatment for PTSD. ${ }^{12}$ There are, however, major differences between the methodological quality of these reviews, making direct comparison problematic. ${ }^{13}$ Given the inconsistent findings of previous meta-analyses and the increasing number of randomised controlled trials (RCTs) of pharmacological treatments, the World Health Organization (WHO) commissioned an update of the information obtained by the most methodologically robust systematic reviews published to date: those by NICE, ACPMH and the Cochrane Collaboration. ${ }^{7,8,11}$ We reviewed RCTs that assessed the efficacy of pharmacological treatment compared with placebo control groups at reducing traumatic stress symptoms in individuals experiencing PTSD.

\section{Method}

All double-blind, randomised, placebo-controlled and comparative trials of the pharmacological treatment of PTSD completed from October 2005 (to ensure all eligible trials not published at the time of the NICE, Cochrane and ACPMH searches would be included) were considered in our primary and additional searches, covering 13 separate databases. Trials completed before October 2005 that were included in the NICE, Cochrane and ACPMH reviews were also considered. Published and unpublished abstracts and reports were sought out in any language. Studies were not excluded on the basis of differences between them such as sample size and duration. Pharmacotherapy trials in which there was ongoing or newly initiated trauma-focused psychotherapy or where the experimental medication served as an augmentation agent to ongoing pharmacotherapy were excluded. Pharmacotherapy trials in which there was ongoing supportive counselling were allowed provided it was not initiated during the course of the treatment, on the basis that this is common in trials and the limited evidence for supportive counselling. ${ }^{14}$ Open label trials were not considered. Our review followed the Preferred Reporting Items for Systemic Reviews and Meta-analyses (PRISMA) checklist and reporting guidance. $^{15}$

\section{Participants}

All studies of participants with PTSD according to ICD or DSM criteria were eligible. ${ }^{3,4}$ There was no restriction on the basis of onset, duration or severity of PTSD symptoms, or on the presence of comorbid disorders, trauma type, age or gender of participants. 


\section{Interventions}

Pharmacological treatments for adults with PTSD, in which the comparator was a placebo or other medication, were eligible for inclusion.

\section{Outcome measures}

The primary outcomes of interest were clinician-administered continuous measures of symptom severity such as the Clinician Administered PTSD Scale. Self-rated PTSD symptom scales were considered separately. The total number of participants who left the trial early for any reason was used as a proxy measure of treatment acceptability.

\section{Search strategy}

We conducted a primary bibliographic database search of Medline, Medline In Process, EMBASE, the Health Management Information Consortium (HMIC) database, PsycINFO, ASSIA and CINAHL using the Ovid interface on 22 February 2013. In order to avoid language bias, we separately searched (using the same search strategy, and in consultation with regional experts) the Japanese, Chinese and WHO regional databases (Spanish, Russian and Portuguese languages). This initial broad search was intended to identify not only the RCTs of interest but also reviews of pharmacotherapy for PTSD. The comprehensive search term used (see online Appendix DS1) was created by amalgamating the previous search strategies from the NICE, Cochrane and ACPMH guideline reviews with an updated list of medications. Additional searches for published and unpublished studies were made in the National Center for PTSD PILOTS database, the Cochrane Library, the Controlled Trials Register, Web of Knowledge, OpenSIGLE and Google Scholar. Reference lists of all selected studies and reviews were further scrutinised for any additional RCTs. An expert group was consulted to identify any additional studies they were aware of. Authors of identified studies were contacted to request data if outcome information was missing.

\section{Study selection}

One reviewer transferred the initial search hits and studies included in the earlier systematic reviews into EndNoteX4 software for Windows. Duplicates were removed. Two reviewers then independently screened the titles and abstracts. Studies that were clearly irrelevant were excluded; potentially relevant ones were assessed for inclusion as full texts. Any discrepancies between reviewers' decisions were resolved by discussion with a third reviewer.

\section{Data extraction and risk of bias assessment}

All data from newly identified studies were double-extracted by two independent reviewers into a standardised table and any discrepancies were discussed with a third reviewer. Data for change from baseline to end-point were extracted when available, otherwise end-point data were used. Continuous data were extracted for clinician-administered PTSD symptom severity using the Clinician Administered PTSD Scale as the gold standard; for self-rated PTSD, the Davidson Trauma Scale was used as the gold standard. If these scales were not used, data from alternative scales were extracted. Dichotomous data were extracted for number of people withdrawing from the trial using total number of participants in the group as the denominator. One reviewer entered the outcome data into Review Manager 5 software for Windows, which was then checked by another reviewer. Data from studies included in previous systematic reviews were doubleextracted by two independent reviewers, cross-checked for accuracy and any discrepancies were discussed with a third reviewer.

\section{Risk of bias}

Two reviewers, using the domain-based evaluation method recommended by the Cochrane Collaboration, ${ }^{16}$ independently assessed risk of bias in individual studies for each trial. This method considers the following domains: random sequence generation; allocation concealment; masking of participants and personnel; masking of outcome assessment; incomplete outcome data; selective reporting; and other sources of bias. Any discrepancies between reviewers' decisions were resolved by discussion with a third reviewer. Risk of bias across studies was assessed by considering publication bias through the visual examination of funnel plots.

\section{Statistical analysis}

Review Manager 5 software was used to synthesise data using meta-analysis and to provide forest plots for dichotomous and continuous data. Confidence intervals of $95 \%$ were used for all analyses. Categorical outcome measures such as leaving the study early were analysed using relative risk (RR) calculations. For continuous data, standardised mean differences (SMD) were used. The degree of heterogeneity between studies was calculated using the $I^{2}$ statistic. Where this was less than $30 \%$, indicating a mild degree of heterogeneity, a fixed effects model was used; a random effects model was used when $I^{2}$ was greater than $30 \%$. Data were analysed from the intention to treat (ITT) sample in the 'once randomised always analysed' fashion where possible, to avoid effects of bias from completers-only analyses. Analyses were performed for individual drugs and, in order to maximise the information available from data synthesis, whenever possible for classes of drugs (e.g. tricyclic antidepressants, SSRIs) and trauma type (e.g. combat trauma, sexual trauma, interpersonal violence trauma, all non-combat trauma).

\section{Results}

The database search yielded 13634 records and an additional 74 were identified from other sources. From these, 4613 duplicates were removed leaving 9095 records. These were screened and 8064 irrelevant studies were removed. This left 1031 abstracts from which 896 were removed as ineligible. This left 135 full-text articles which were reviewed to find 84 not meeting the inclusion criteria. A total of 51 studies were included in this systematic review (Fig. 1). Sixteen new studies were found from our database search. ${ }^{17-32}$ The remaining 35 were found in previous reviews. An additional 28 studies were identified from the NICE guidelines, of which five did not meet our inclusion criteria. ${ }^{33-37}$ This left 23 studies included from the NICE guidelines (references 38-54 plus six unpublished studies A-F in Appendix 1). Thirty-five studies were identified in the Cochrane review, of which 19 were already included in the NICE review and removed as duplicates. A further four used completer-only data and were not included; ${ }^{55-58}$ another allowed concomitant psychotropic medications and was excluded. ${ }^{59}$ This left an additional 11 studies from the Cochrane review, ${ }^{60-70}$ which were included. There were 12 additional pharmacotherapy studies identified from the ACPMH guidelines, of which seven were already present in the above reviews and were removed as duplicates. A further four did not meet our inclusion criteria, ${ }^{71-74}$ leaving one additional study which was included. ${ }^{75}$ 


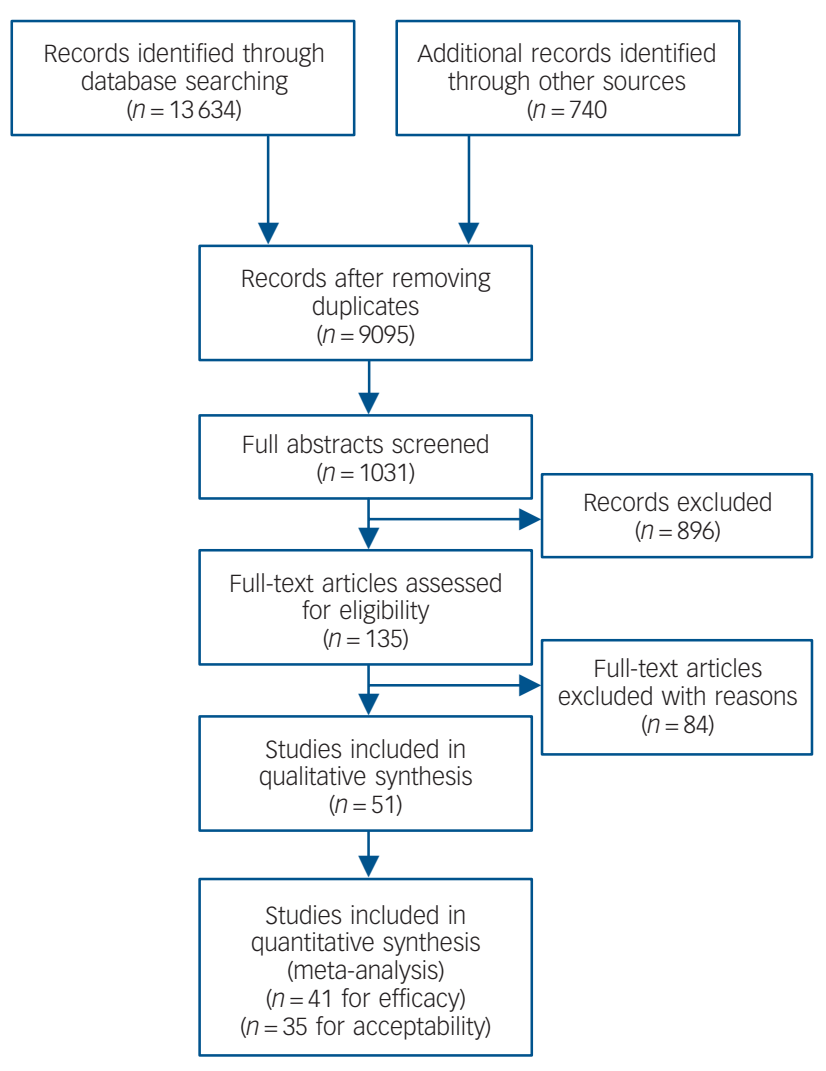

Fig. 1 Study search profile.

\section{Description of studies}

The characteristics of the 51 RCTs included in this review are summarised in online Table DS1. Only three of the studies did not employ a placebo comparator arm. ${ }^{28,65,67}$ There were 31 SSRI trials, 14 of which assessed sertraline, ${ }^{21,26,38,42,43,45,54,61,65,67,68, \mathrm{~A}, \mathrm{C}, \mathrm{D}}$ nine assessed fluoxetine, ${ }^{23,40,47,51,52,69,70,75, \mathrm{~B}}$ seven assessed paroxetine, ${ }^{22,32,50,53,64, \mathrm{E}, \mathrm{F}}$ one citalopram, ${ }^{68}$ one escitalopram, ${ }^{27}$ and one fluvoxamine. ${ }^{28}$ There were three tricyclic antidepressant trials, ${ }^{42,49,66}$ and three monoamine oxidase inhibitor (MAOI) trials. ${ }^{48,49,60}$ Another six trials assessed other antidepressants, ${ }^{18,44,46,65,67, \mathrm{~A}}$ and a further ten trials assessed other agents. $17,18,20,24,25,29,30,39,62,63$ The average sample size was 130 (range 13-538), the average age of participants was 41 years (range 18-82) and $54 \%$ of participants were women. The average duration of the trials was 12.4 weeks (range 4-36). Thirty-four studies were based in the USA, five were international, four were from Israel and there was one each from Brazil, China, Iran, South Africa and Turkey. The location was unclear in three studies. The predominant trauma $(>50 \%)$ was combat in 13 studies, physical/sexual assault in eight, physical assault alone in four, sexual assault alone in four, natural disaster in two and road traffic accidents in two. For 18 studies participants had been exposed to various traumas with no one type accounting for over $50 \%$.

\section{Risk of bias assessments}

Risk of bias assessments are included in online Table DS1. Fourteen of the studies included enough information on adequate random sequence generation to be judged as having a low risk of bias; the remainder were unclear. Only eight studies included an adequate description of allocation concealment. All 51 studies described themselves as 'double blind' but only eight provided sufficient information to judge the masking of participants, personnel and outcome assessors as being of low risk. Incomplete outcome data were addressed adequately in 15 studies. Thirtyeight of the studies were deemed to be free from selective reporting.

\section{Efficacy of pharmacotherapy}

Data from 21 studies $(n=3932)$ were available for inclusion in a meta-analysis of reduction in severity of PTSD symptoms for any SSRI $v$. placebo (Fig. 2). This found a small positive effect for SSRIs when grouped together. The results of meta-analyses for individual drugs, which had been tested against placebo in at least two RCTs, are shown in Table 1. Three drugs were significantly superior to placebo on either clinician- and self-rated PTSD symptom severity combined (paroxetine) or clinician-rated PTSD symptom severity alone (fluoxetine and venlafaxine). We found insufficient evidence to support the preferential use of individual agents in either combat-related or non-combat-related trauma (Table 2).

\section{Discussion}

This systematic review found statistically significant evidence on meta-analysis for three pharmacological agents $v$. placebo in the treatment of PTSD (fluoxetine, paroxetine and venlafaxine) but no evidence for brofaromine, olanzapine, sertraline or topiramate. Four drugs - amitriptyline, GR205171 (a neurokinin-1 antagonist), mirtazapine and phenelzine - showed superiority over placebo in single RCTs, whereas eleven did not: alprazolam, citalopram, desipramine, escitalopram, imipramine, lamotrigine, nefazadone, risperidone, tiagabine and valproate semisodium. When metaanalyses were undertaken by class of drug rather than individual drug, SSRIs were found to perform better than placebo. The absence of sufficient data precluded meta-analyses of other drug classes. The absence of difference in numbers of individuals leaving the study early for any reason suggests that the drugs included were well tolerated overall.

The effect sizes for pharmacological treatments for PTSD compared with placebo are low and inferior to those reported for psychological treatments with a trauma focus over waiting-list or treatment as usual controls. ${ }^{14}$ They are, however, similar to those found for antidepressants for depression compared with placebo. $^{76}$ Unfortunately, the absence of a common control condition and head-to-head pharmacological $v$. psychological treatment trials makes comparison of the relative efficacies of these treatment approaches difficult. This is compounded by the fact that a significant number of participants in psychological treatment trials were continuing pre-existing pharmacological treatment at the same time.

It is well accepted that a well-masked, placebo-controlled trial is a tougher test for an experimental intervention than a trial with a waiting-list control. The UK's NICE guidelines development group attempted to address this by determining a higher effect size threshold for psychological treatments than pharmacological ones $(0.8 v .0 .5),{ }^{7}$ but it is unclear whether such arbitrary cut-offs may have introduced bias against either form of treatment. What is clear is the marked effect of the placebo in several of the trials reported in this review. For example, in the two venlafaxine studies the mean reduction in PTSD symptoms of those on placebo was greater than $40 \% .{ }^{18,47}$ There is a need for RCTs of specific psychological interventions compared with an adequate non-specific psychological intervention. It is only through such trials and direct head-to-head comparisons that the relative effectiveness of differing treatment approaches could be established. The current meta-analyses are a later iteration of the 


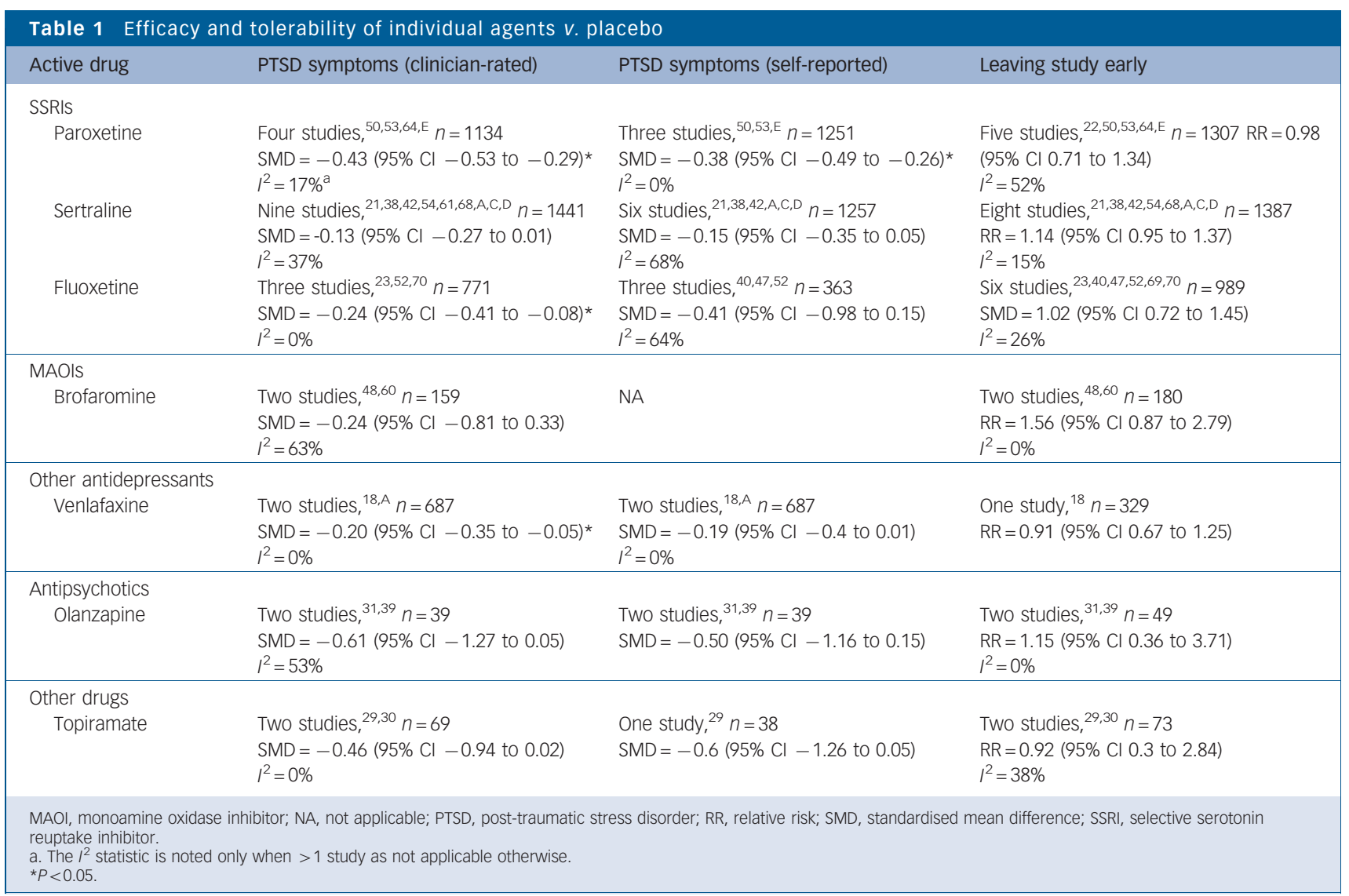

evidence used to determine what to recommend for recent WHO guidelines. ${ }^{77} \mathrm{~A}$ WHO guidelines development group examined this evidence and recommended antidepressants as a second line of treatment of PTSD when psychological interventions with known efficacy did not work or were not available. The recently updated Australian guidelines also concluded that pharmacological interventions should not be preferentially used as a routine first treatment of PTSD over trauma-focused psychological treatments. ${ }^{78}$ There are various other reasons for considering the prescription of antidepressants, including

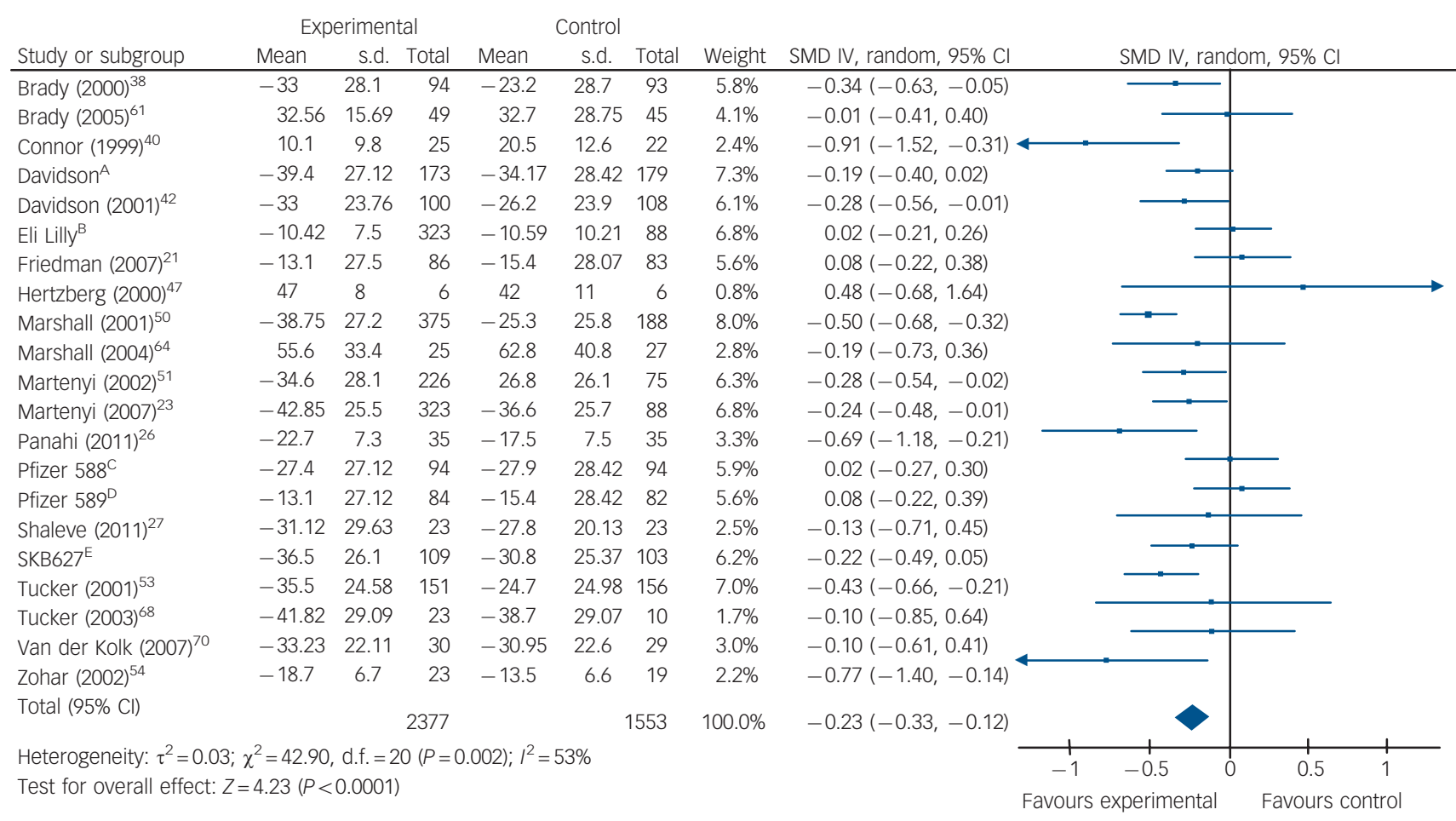

Fig. 2 Meta-analysis of selective serotonin reuptake inhibitors v. placebo (SMD, standardised mean difference). 
Table 2 Trauma type subanalysis of individual agents $v$. placebo

\begin{tabular}{|c|c|c|c|c|c|}
\hline Active drug & Combat & Sexual & Interpersonal violence & $\begin{array}{l}\text { Natural } \\
\text { disaster/ } \\
\text { accident }\end{array}$ & $\begin{array}{l}\text { All non-combat trauma } \\
\text { combined }\end{array}$ \\
\hline \multicolumn{6}{|l|}{ SSRIS } \\
\hline Paroxetine & NA & NA & $\begin{array}{l}\text { One study, }{ }^{64} n=52 \\
\text { SMD }=-0.19 \\
(95 \% \mathrm{Cl}-0.73 \text { to } 0.36)\end{array}$ & NA & $\begin{array}{l}\text { One study, }{ }^{64} n=52 \\
\text { SMD }=-0.19 \\
(95 \% \mathrm{Cl}-0.73 \text { to } 0.36)\end{array}$ \\
\hline \multirow[t]{2}{*}{ Sertraline } & Four studies, ${ }^{21,26,54, D} n=447$ & One study, ${ }^{38} n=183$ & Two studies, ${ }^{61, A} n=446$ & NA & Five studies, ${ }^{42,61, A, C, D} n=1008$ \\
\hline & $\begin{array}{l}\mathrm{SMD}=-0.26 \\
(95 \% \mathrm{Cl}-0.68 \text { to } 0.16) \\
I^{2}=77 \%^{\mathrm{a}}\end{array}$ & $\begin{array}{l}\mathrm{SMD}=-0.30 \\
(95 \% \mathrm{Cl}-0.59 \text { to }-0.01)^{\star}\end{array}$ & $\begin{array}{l}\mathrm{SMD}=-0.15 \\
(95 \% \mathrm{Cl}-0.34 \text { to } 0.04) \\
I^{2}=68 \%\end{array}$ & & $\begin{array}{l}\mathrm{SMD}=-0.11 \\
(95 \% \mathrm{Cl}-0.23 \text { to } 0.02) \\
I^{2}=14 \%\end{array}$ \\
\hline \multirow[t]{2}{*}{ Fluoxetine } & Two studies, ${ }^{47,52} n=313$ & Two studies, ${ }^{23,40} n=458$ & One study, ${ }^{70} n=59$ & NA & Three studies, ${ }^{29,40,47} n=517$ \\
\hline & $\begin{array}{l}\mathrm{SMD}=-0.12 \\
(95 \% \mathrm{Cl}-0.73 \text { to } 0.50) \\
I^{2}=37 \%\end{array}$ & $\begin{array}{l}\mathrm{SMD}=-0.52 \\
(95 \% \mathrm{Cl}-1.16 \text { to } 0.13) \\
I^{2}=76 \%\end{array}$ & $\begin{array}{l}\mathrm{SMD}=-0.10 \\
(95 \% \mathrm{Cl}-0.61 \text { to } 0.41)\end{array}$ & & $\begin{array}{l}\mathrm{SMD}=-0.36 \\
(95 \% \mathrm{Cl}-0.75 \text { to } 0.02) \\
I^{2}=58 \%\end{array}$ \\
\hline \multicolumn{6}{|l|}{ MAOIS } \\
\hline \multirow[t]{2}{*}{ Brofaromine } & One study, ${ }^{60} n=114$ & NA & One study, ${ }^{48} n=55$ & NA & NA \\
\hline & $\begin{array}{l}\mathrm{SMD}=0.01 \\
(95 \% \mathrm{Cl}-0.36 \text { to } 0.38)\end{array}$ & & $\begin{array}{l}\mathrm{SMD}=-0.58 \\
(95 \% \mathrm{Cl}-1.58 \text { to } 0.02)\end{array}$ & & \\
\hline \multicolumn{6}{|c|}{ Other antidepressants } \\
\hline Venlafaxine & NA & NA & $\begin{array}{l}\text { Two studies, }{ }^{18, \mathrm{~A}} n=687 \\
\text { SMD }=-0.20 \\
(95 \% \mathrm{Cl}-0.35 \text { to }-0.05)^{*} \\
I^{2}=0 \%\end{array}$ & NA & NA \\
\hline \multicolumn{6}{|l|}{ Antipsychotics } \\
\hline \multirow[t]{3}{*}{ Olanzapine } & NA & One study, ${ }^{39} n=11$ & One study, ${ }^{31} n=28$ & NA & Two studies, ${ }^{31,39} n=39$ \\
\hline & & $\mathrm{SMD}=0.16$ & $\mathrm{SMD}=-0.93$ & & $\mathrm{SMD}=-0.61$ \\
\hline & & (95\% Cl -1.07 to 1.39$)$ & $(95 \% \mathrm{Cl}-1.71 \text { to }-0.14)^{*}$ & & $\begin{array}{l}(95 \% \mathrm{Cl}-1.27 \text { to } 0.05) \\
I^{2}=53 \%\end{array}$ \\
\hline \multicolumn{6}{|l|}{ Other drugs } \\
\hline \multirow[t]{2}{*}{ Topiramate } & NA & One study, ${ }^{29} n=38$ & One study, ${ }^{30} n=32$ & NA & Two studies, ${ }^{29,30} n=69$ \\
\hline & & $\begin{array}{l}\mathrm{SMD}=-0.39 \\
(95 \% \mathrm{Cl}-1.03 \text { to } 0.25)\end{array}$ & $\begin{array}{l}\mathrm{SMD}=-2.38 \\
(95 \% \mathrm{Cl}-3.33 \text { to } 1.43)^{*}\end{array}$ & & $\begin{array}{l}\mathrm{SMD}=-0.46 \\
(95 \% \mathrm{Cl}-0.94 \text { to } 0.02) \\
I^{2}=0 \%\end{array}$ \\
\hline $\begin{array}{l}\text { MAOI, monoamine } \\
\text { a. The } I^{2} \text { statistic is } \\
{ }^{*} P<0.05 \text {. }\end{array}$ & $\begin{array}{l}\text { hibitor; NA, not applicable; SMD } \\
\text { y when }>1 \text { study as not applical }\end{array}$ & $\begin{array}{l}\text { standardised mean difference; } \\
\text { le otherwise. }\end{array}$ & & & \\
\hline
\end{tabular}

concurrent depression, lack of availability of psychological treatments, failure to respond to or tolerate psychological treatments and the personal preference of the individual with PTSD.

The variation in efficacy between different agents is striking and could be explained by a number of factors. First, there may be real differences between drugs, even those in the same family. For example, paroxetine's superior efficacy over sertraline may possibly be explained by its increased dopamine receptor activity. Differences in the pharmacology of phenelzine and brofaromine are also marked, and grouping all drugs in one class together seems less desirable than considering each one individually. This confirms previous observation that class membership does not confer the same level of efficacy in the treatment of PTSD. ${ }^{11}$ This meta-analysis supports this assertion, with the SSRIs paroxetine and fluoxetine having better evidence of efficacy than sertraline. It is interesting to note, however, that despite failing to show superiority over placebo, sertraline showed equivalence to venlafaxine in one of the studies included. ${ }^{\mathrm{A}}$ This may be a result of the strength of placebo effect varying across studies.

The differences found between paroxetine and sertraline could be due to chance or lack of power, but it is noteworthy that over 1000 individuals were included in the meta-analyses of both paroxetine and sertraline, which suggests that power was not the issue. The same cannot be said for the majority of drugs reviewed, the evaluation of which was based on single RCTs with fewer than 100 participants. This review added 15 new RCTs to the evidence previously reported in systematic reviews but added no new trials for three of the four drugs recommended in the NICE guidelines (mirtazapine, amitriptyline and phenelzine). Of particular note is that new evidence resulted in drugs not recommended by NICE (fluoxetine and venlafaxine) now meeting the requirements laid down by NICE for recommendation as a second-line treatment. This review used particular rigour in assessing studies. Most of the other reviews that have concluded more favourably about pharmacotherapy grouped drugs from the same class together, ${ }^{10,11}$ did not include unpublished studies, ${ }^{79,80}$ and adopted different inclusion criteria. ${ }^{8,10,79,80}$ This probably accounts for differences in conclusions between different meta-analyses despite apparently having the same raw data available. For example, sertraline performed significantly better than placebo in two recent metaanalyses, ${ }^{79,80}$ which did not include the two unpublished studies included in our review. ${ }^{\mathrm{C}, \mathrm{D}}$

\section{Study limitations}

There were, however, some important methodological flaws in the studies identified in this review as illustrated by the risk of bias assessment undertaken. Clinical and statistical heterogeneity was apparent in the meta-analyses; this makes interpretation and generalisation across different trauma populations difficult. A major issue was that, despite having systematically tried to access unpublished data on the studies without ITT efficacy data, sufficient data for analysis were only available from only 41 of the 51 studies included. This raises the risk of outcome reporting bias. ${ }^{81}$ Incorrect definition of the ITT sample population was a 
problem. This is an important principle where data from every person who is randomised should be included in the analysis of efficacy. Participants might leave a study because of adverse effects, failed efficacy or greater symptom severity at baseline; not including their data in the analysis leads to bias, as a treatment might appear to be more effective than it is. Another important issue to consider is that this review considers drug monotherapy as opposed to drug or placebo in combination with psychological treatment. This evidence cannot, therefore, be used to consider whether or not pharmacotherapy augments psychological treatment for PTSD; many people with the disorder do receive both.

Several of the new studies identified by our search defined their ITT population as participants who received at least one dose of the study medication and received at least one post-baseline assessment. This could exclude some participants from analysis who had received treatment but not been assessed after the baseline. The most extreme case was a study of fluoxetine that defined ITT in this way, ${ }^{23}$ but measured PTSD symptom severity only at baseline and end-point, so was actually a completers sample. We decided to include these studies in our analysis but acknowledge that this affects the reliability of the results.

\section{Implications}

Pharmacological interventions for PTSD can be effective but the magnitude of effect unfortunately is small, and the clinical relevance of this small effect is unclear. This review supports the use of paroxetine, venlafaxine and fluoxetine as pharmacological interventions for PTSD. For most drugs, there remains inadequate evidence regarding efficacy for PTSD, pointing to the need for more research in this area to confirm the utility of pharmacological treatments for this disorder.

Mathew Hoskins, MRCPsych, Jennifer Pearce, BSC, Andrew Bethell, BSC, Liliya Dankova, BSC, Cardiff University, Cardiff, UK; Corrado Barbui, MD, Department of Public Health and Community Medicine, Section of Psychiatry, University of Verona, Verona, Italy: Wietse A. Tol, PhD, Johns Hopkins Bloomberg School of Public Health, Baltimore, USA; Mark van Omm, Baltinore, USA; Mark van Ommeren, $\mathrm{H} D$, World Healt Organization, Geneva, Switzerland, Joop de Jong, $M D$, PhD, Vije Universiteit, Amsterdam, The Netherlands; Soraya Seedat, MD, Stellenbosch University, Stellenbosch, South Africa; Hanhui Chen, MD, Shanghai Mental Health Centre, Shanghai Jiaotong University, Shanghai, China; Jonathan I. Bisson, DM, Cardiff University, Cardiff, UK

Correspondence: Professor Jonathan I. Bisson, Cardiff University, Institute of Psychological Medicine and Clinical Neurosciences, Hadyn Ellis Building, Maindy Road, Cathays, Cardiff CF24 4HQ, UK. Email bissonji@cf.ac.uk

First received 13 Oct 2013, final revision 8 Jun 2014, accepted 16 Jun 2014

\section{Funding}

The World Health Organization supported this work to inform the development of Mental Health Gap Action Programme (mhGAP) guidelines on disorders and problems specifically related to stress. The views expressed in this article are those of the authors solely and do not necessarily represent the views, policies or decisions of their employers.

\section{Acknowledgements}

We acknowledge Jorge Castro and Keiko Sakurai (World Health Organization interns) for assistance in multi-language searches.

\section{Appendix 1}

\section{Unpublished studies}

Further details of the studies listed below are available from the authors.

A. Davidson J, Lipschitz A, Musgnung JJ. Venlafaxine XR and sertraline in posttraumatic stress disorder: a placebo-controlled trial. Appendix 14 of 2nd consultation draft for the NICE (2005) PTSD guidelines.

B. Eli Lilly. Unpublished data. Appendix 14 of 2nd consultation draft for the NICE (2005) PTSD guidelines.
C. Pfizer588. Unpublished data. Appendix 14 of 2nd consultation draft for the NICE (2005) PTSD guidelines.

D. Pfizer589. Unpublished data. Appendix 14 of 2 nd consultation draft for the NICE (2005) PTSD guidelines.

E. SKB627 Bryson H, Lawrinson S, Edwards GJ, Grotzinger KM. A 12 week, double-blind, placebo-controlled, parallel group study to assess the efficacy and tolerability of paroxetine in patients suffering from posttraumatic stress disorder.

F. SKB650 Bryson H, Dillingham KE, Jeffery PJ. A study of the maintained efficacy and safety of paroxetine versus placebo in the long-term treatment of posttraumatic stress disorder.

\section{References}

1 Steel Z, Chey T, Silove D, Marnane C, Bryant RA, van Ommeren M. Association of torture and other potentially traumatic events with mental health outcomes among populations exposed to mass conflict and displacement: a systematic review and meta-analysis. JAMA 2009; 302: 537-49.

2 Karam EG, Andrews G, Bromet E, Petukhova M, Ruscio AM, Salamoun M, et al. The role of Criterion A2 in the DSM-IV diagnosis of post-traumatic stress disorder. Biol Psychiatry 2009; 68: 465-73.

3 World Health Organization. The ICD-10 Classification of Mental and Behavioural Disorders: Clinical Descriptions and Diagnostic Guidelines. WHO, 1992.

4 American Psychiatric Association. Diagnostic and Statistical Manual of Mental Disorders Fourth Edition, Text Revision (DSM-IV-TR). APA, 2000.

5 Brunello N, Davidson JR, Deahl M, Kessler RC, Mendlewicz J, Racagni G, et al. Posttraumatic stress disorder: diagnosis and epidemiology, comorbidity and social consequences, biology and treatment. Neuropsychobiology 2001; 43 : $150-62$.

6 Ferry F, Bolton D, Bunting B, O'Neill S, Murphy S, Devine B. Economic Impact of Post Traumatic Stress in Northern Ireland. Northern Ireland Centre for Trauma and Transformation and University of Ulster Psychology Research Institute, 2010.

7 National Collaborating Centre for Mental Health. Post-traumatic Stress Disorder: The Management of PTSD in Adults and Children in Primary and Secondary Care. British Psychological Society/Royal College of Psychiatrists, 2005.

8 Australian Centre for Posttraumatic Mental Health. Australian Guidelines for the Treatment of Adults with Acute Stress Disorder and Posttraumatic Stress Disorder. ACPMH, 2007.

9 American Psychiatric Association. Practice Guideline for the Treatment of Patients with Acute Stress Disorder and Posttraumatic Stress Disorder. American Psychiatric Press, 2004.

10 Foa EB, Keane TM, Friedman MJ, Cohen J, eds. Effective Treatments for PTSD: Practice Guidelines from the International Society for Traumatic Stress Studies (2 ed). Guilford, 2008.

11 Stein DJ, Zungu-Dirwayi N, Van der Linden GJ, Seedat S. Pharmacotherapy for posttraumatic stress disorder. Cochrane Database of Systematic Reviews 2004; issue 2.

12 Institute of Medicine. Treatment of PTSD: An Assessment of the Evidence. National Academies Press, 2008.

13 Forbes D, Creamer M, Bisson JI, Cohen JA, Crow BE, Foa EB, et al. A guide to guidelines for the treatment of PTSD and related conditions. J Trauma Stress 2010; 23: 537-52.

14 Bisson Jl, Ehlers A, Matthews R, Pilling S, Richards D, Turner S. Psychological treatments for chronic post-traumatic stress disorder: systematic review and meta-analysis. Br J Psychiatry 2007; 190: 97-104.

15 PRISMA Statement. 2009 (http://prisma-statement.org/statement.htm).

16 Higgins JPT, Green S, eds. Cochrane Handbook for Systematic Reviews of Interventions Version 5.1.0. Cochrane Collaboration, 2011.

17 Connor KM, Davidson JR, Weisler RH, Zhang W, Abraham K. Tiagabine for posttraumatic stress disorder: effects of open-label and double-blind discontinuation treatment. Psychopharmacology 2006; 184: 21-5.

18 Davidson J, Baldwin D, Stein DJ, Kuper E, Benattia I, Ahmed S, et al. Treatment of posttraumatic stress disorder with venlafaxine extended release: a 6 month randomized controlled trial. Arch Gen Psychiatry 2006; 63: 1158-65.

19 Davidson JR, Brady K, Mellman TA, Stein MB, Pollack MH. The efficacy and tolerability of tiagabine in adult patients with post-traumatic stress disorder. J Clin Psychopharmacol 2007; 27: 85-8. 
20 Davis LL, Davidson JR, Ward LC, Bartolucci A, Bowden CL, Petty F. Divalproex in the treatment of posttraumatic stress disorder. J Clin Psychopharmacol 2008; 281: 84-8.

21 Friedman MJ, Marmar CR, Baker DG, Sikes CR, Farfel GM. Randomized double blind comparison of sertraline for posttraumatic stress disorder in a Department of Veterans Affairs setting. J Clin Psychiatry 2007; 68: 711-20.

22 Wang $\mathrm{H}-\mathrm{H}$, Tan Q-R, Wang Z-Z, Wang H-N, Cheng C-G, Chen Y-C, et al. A randomised controlled study on prevention of posttraumatic stress disorder. J Clin Psychol Med 2009; 1: 1-3.

23 Martenyi F, Brown EB, Caldwell CD. Failed efficacy of fluoxetine in the treatment of posttraumatic stress disorder. J Clin Psych 2007; 27: 166-70.

24 Matthew SJ, Vythilingam M, Murrough JW, Feder A, Luckenbaugh DA, Kinkead $B$, et al. A selective neurokinin-1 receptor antagonist in chronic PTSD: a randomized, double blind, placebo controlled proof of concept trial. Euro Neuropsychopharmacol 2011; 21: 221-9.

25 Padala PR, Madison J, Monnahan M, Marcil W, Price P, Ramaswamy S, et a Risperidone monotherapy for posttraumatic stress disorder related to sexual assault and domestic abuse in women. Int Clin Psychopharmacol 2006; 21 275-80

26 Panahi Y, Moghaddam BR, Sahebkar A, Sahebkar A, Nazari MA, Beiraghdar F, et al. A randomized, double blind, placebo controlled trial on the efficacy and tolerability of sertraline in Iranian veterans with post-traumatic stress disorder. Psychol Med 2011; 41: 2159-66.

27 Shalev AY, Ankri Y, Israeli-Shalev Y, Peleg T, Adessky R, Freedman S. Prevention of posttraumatic stress disorder by early treatment. Arch Gen Psychiatry 2011; 69: 166-76.

28 Spivak B, Strous RD, Shaked G, Shabash E, Kotler M, Weizman A. Reboxetine versus fluvoxamine in treatment of motor vehicle accident related posttraumatic stress disorder. J Clin Psychopharmacol 2006; 26: $152-6$.

29 Tucker P, Trautman RP, wyatt DB, Thompson J, Wu SC, Capece JA, et al. Efficacy and safety of topiramate monotherapy in civilian posttraumatic stress disorder: a randomized, double blind, placebo controlled trial. J Clin Psychiatry 2007; 68: 201-6.

30 Yeh MS, Mari JJ, Costa MC, Andreoli SB, Bressan RA, Mello MF. A double blind, randomized controlled trial to study the efficacy of topiramate in a civilian sample of PTSD. CNS Neurosci Ther 2010; 175: 305-10.

31 Carey P, Suliman S, Ganesan K, Seedat S, Stein DJ. Olanzapine monotherapy in posttraumatic stress disorder: Efficacy in a randomized, double-blind, placebo-controlled study. Hum Psychopharmacol 2012; 27: 386-91.

32 Petrakis IL, Ralevski E, Desai N, Trevisan L, Gueorguieva R, Rounsaville B, et al. Noradrenergic vs serotonergic antidepressant with or without naltrexone for veterans with PTSD and comorbid alcohol dependence. Neuropsychopharmacology 2012; 37: 996-1004.

33 Cohen H, Kaplan Z, Kotler M, Kouperman I, Moisa R, Grisaru N. Repetitive transcranial magnetic stimulation of the right dorsolateral prefrontal cortex in posttraumatic stress disorder: a double-blind, placebo-controlled study. Am J Psychiatry 2004; 161: 515-24.

34 Frommberger U, Stieglitz RD, Nyberg E, Richter H, Novelli FU, Angenendt J. Comparison between paroxetine and behaviour therapy in patients with posttraumatic stress disorder (PTSD): a pilot study. Int J Psychiatry Clin Practice 2004; 8: 19-23.

35 Hamner MB, Faldowski RA, Ulmer HG, Frueh BC, Huber MG, Arana GW. Adjunctive risperidone treatment in post-traumatic stress disorder: a preliminary controlled trial of effects on comorbid psychotic symptoms. Int Clin Psychopharmacol 2003; 18: 1-8.

36 Kosten TR. Alexithymia as a predictor of treatment response in posttraumatic stress disorder. J Trauma Stress 1992; 5: 563-73.

37 Stein MB, Kline NA, Matloff JL. Adjunctive olanzapine for SSRI resistant combat-related PTSD: a double-blind, placebo-controlled study. Am J Psychiatry 2002; 159: 1777-9.

38 Brady K, Pearlstein T, Asnis GM, Baker D, Rothbaum B, Sikes CR. Efficacy and safety of sertraline treatment of posttraumatic stress disorder. Arch Gen Psychiatry 2000; 283: 1837-44

39 Butterfield $\mathrm{Ml}$, Becker ME, Connor KM, Sutherland S, Churchill LE, Davidson JR. Olanzapine in the treatment of post-traumatic stress disorder: a pilot study. Int Clin Psychopharmacol 2001; 16: 197-203.

40 Connor KM, Sutherland SM, Tupler LA, Malik ML, Davidson JR. Fluoxetine in post-traumatic stress disorder: randomised, double-blind study. Br J Psychiatry 1999; 175: 17-22.

41 Davidson JR, Kudler $\mathrm{H}$, Smith R, Mahorney SL, Lipper S, Hammett E. Treatment of posttraumatic stress disorder with amitriptyline and placebo. Arch Gen Psychiatry 1990; 47: 259-66.

42 Davidson J, Pearlstein T, Londborg P, Brady KT, Rothbaum B, Bell J. Efficacy of sertraline in preventing relapse of posttraumatic stress disorder: results of a 28-week double-blind, placebo-controlled study. Am J Psychiatry 2001; 158: $1974-81$

43 Davidson JR, Rothbaum BO, van der Kolk BA, Sikes CR, Farfel GM Multicenter, double-blind comparison of sertraline and placebo in the treatment of posttraumatic stress disorder. Arch Gen Psychiatry 2001; 58 485-92.

44 Davidson JR, Weisler RH, Butterfield MI, Casat CD, Connor KM, Barnett S Mirtzapine vs. placebo in posttraumatic stress disorder: a pilot trial. Biol Psychiatry 2003; 53: 188-91.

45 Davidson JR. Remission in post-traumatic stress disorder (PTSD): effects of sertraline as assessed by the Davidson Trauma Scale, Clinical Global Impressions and the Clinician-Administered PTSD scale. Int Clin Psychopharmacol 2004; 19: 85-7.

46 Davis LL, Jewell ME, Ambrose S, Farley J, English B, Bartolucci A. A placebocontrolled study of nefazadone for the treatment of chronic posttraumatic stress disorder. J Clin Psychopharmacol 2001; 24: 291-7.

47 Hertzberg MA, Feldman ME, Beckham JC, Kudler HS, Davidson JR. Lack of efficacy for fluoxetine in PTSD: a placebo controlled trial in combat veterans. Ann Clin Psychiatry 2000; 12: 101-5.

48 Katz RJ, Lott MH, Arbus $\mathrm{P}$, Crocq L, Herlobsen $\mathrm{P}$, Lingjaerde $\mathrm{O}$. Pharmacotherapy of post-traumatic stress disorder with a novel psychotropic. Anxiety 1994; 1: 169-174.

49 Kosten TR, Frank JB, Dan E, McDougle CJ, Giller EL. Pharmacotherapy for posttraumatic stress disorder using phenelzine or imipramine. J Nerv Ment Dis 1991; 179: 366-70.

50 Marshall RD, Beebe KL, Oldham M, Zaninelli R. Efficacy and safety of paroxetine treatment for chronic PTSD: a fixed-dose, placebo-controlled study. Am J Psychiatry 2001; 158: 1982-8.

51 Martenyi $\mathrm{F}$, Brown EB, Zhang $\mathrm{H}$, Koke SC, Prakash A. Fluoxetine v. placebo in prevention of relapse in post-traumatic stress disorder. Br J Psychiatry 2002; 181: 315-20.

52 Martenyi F, Brown EB, Zhang H, Prakash A, Koke SC. Fluoxetine versus placebo in posttraumatic stress disorder. J Clin Psychiatry 2002; 63: 199-206.

53 Tucker $\mathrm{P}$, Zaninelli R, Yehuda R, Ruggiero L, Dillingham K, Pitts CD. Paroxetine in the treatment of chronic posttraumatic stress disorder: results of a placebo-controlled, flexible-dosage trial. J Clin Psychiatry 2001; 62: 860-8.

54 Zohar J, Amital D, Miodownik C, Kotler M, Bleich A, Lane RM. Double-blind placebo-controlled pilot study of sertraline in military veterans with posttraumatic stress disorder. J Clin Psychopharmacol 2002; 22: 190-5.

55 Kaplan Z, Amir M, Swartz M, Levine J. Inositol treatment of posttraumatic stress disorder. Anxiety 1996; 2: 51-2.

56 Chung MY, Min KH, Jun YJ, Kim SS, Kim WC, Jun EM. Efficacy and tolerability of mirtazapine and sertraline in Korean veterans with posttraumatic stress disorder: a randomized open label trial. Hum Psychopharmacol 2004; 19 : 489-94.

57 Shestatzky M, Greenberg D, Lerer B. A controlled trial of phenelzine in posttraumatic stress disorder. Psychiatr Res 1988; 24: 149-55.

58 Smajkic A, Weine S, Djuric-Bijedic Z, Boskailo E, Lewis J, Pavkovic I. Sertraline, paroxetine, and venlafaxine in refugee posttraumatic stress disorder with depression symptoms. J Trauma Stress 2001; 14: 445-52.

59 Reich DB, Winternitz S, Hennen J, Watts T, Stanculescu C. A preliminary study of risperidone in the treatment of posttraumatic stress disorder related to childhood abuse in women. J Clin Psychiatry 2004; 65: 1601-5.

60 Baker DG, Diamond BI, Gillette G, Hamner M, Katzelnick D, Keller T. A doubleblind randomized placebo-controlled multi-center study of brofaromine in the treatment of posttraumatic stress disorder. Psychopharmacology 1995; 122: 386-9.

61 Brady KT, Sonne S, Anton RF, Randall CL, Back SE, Simpson K. Sertraline in the treatment of co-occurring alcohol dependence and posttraumatic stress disorder. Alcohol Clin Exp Res 2005: 29: 395-401.

62 Braun P, Greenberg D, Dasberg H, Lerer B. Core symptoms of posttraumatic stress disorder unimproved by alprazolam treatment. J Clin Psychiatry 1991; 51: $236-8$.

63 Hertzberg MA, Butterfield MI, Feldman ME, Beckham JC, Sutherland SM, Connor KM. A preliminary study of lamotrigine for the treatment of posttraumatic stress disorder. Biol Psychiatry 1999; 45: 1226-9.

64 Marshall RD, Lewis-Fernandez R, Blanco C, Simpson HB, Lin S-H, Vermes D, et al. A controlled trial of paroxetine for chronic PTSD, dissociation and interpersonal problems in mostly minority adults. Depress Anxiety 2007; 24: 77-84.

65 McRae AL, Brady KT, Mellman TA, Sonn SC, Killeen TK, Timmerman MA. Comparison of nefazodone and sertraline for the treatment of posttraumatic stress disorder. Depress Anxiety 2004; 19: 190-6. 
66 Reist C, Kauffmann CD, Haier RJ, Sangdahl C, DeMet EM, Chicz-DeMet A. A controlled trial of desipramine in 18 men with posttraumatic stress disorder. Am J Psychiatry 1989; 146: 513-6.

67 Saygin MZ, Sungur MZ, Sabol EU, Cetinkaya P. Nefazodone versus sertraline in treatment of posttraumatic stress disorder. Bull Clin Psychopharmacol 2002; 12: $1-5$

68 Tucker P, Potter-Kimball R, wyatt DB, Parker DE, Burgin C, Jones DE. Can physiologic assessment and side effects tease out differences in PTSD trials? A double-blind comparison of citalopram, sertraline, and placebo. Gen Psychopharmacol 2003; 37: 135-49.

69 Van der Kolk BA, Dreyfuss D, Michaels M, Shera D, Berkowitz R, Fisler R. Fluoxetine treatment in posttraumatic stress disorder. J Clin Psychiatry 1994; 55: 517-22.

70 Van der Kolk BA, Spinazzola J, Blaustein ME, Hopper JW, Hopper EK, Korn DL, et al. A randomized clinical trial of eye movement desensitization and reprocessing (EMDR), fluoxetine and pill placebo in the treatment of posttraumatic stress disorder: treatment effects and long-term maintenance. J Clin Psychiatry 2007; 68: 37-46.

71 Mooney P, Oakley J, Ferriter M, Travers R. Sertraline as a treatment for PTSD: a systematic review and meta-analysis. Irish J Psychol Med 2004; 21: 100-3.

72 Otto MW, Hinton D, Korbly NB, Chea A, Ba P, Gershuny BS, et al. Treatment of pharmacotherapy-refractory posttraumatic stress disorder among Cambodian refugees: a pilot study of combination treatment with cognitive-behavior therapy vs sertraline alone. Behav Res Ther 2003; 41: $1271-6$

73 Rothbaum BO, Cahill SP, Foa EB, Davidson JR, Compton J, Connor KM, et al Augmentation of sertraline with prolonged exposure in the treatment of posttraumatic stress disorder. J Trauma Stress 2006; 19: 625-38.
74 Stein MB, Kline NA, Matloff JL. Adjunctive olanzapine for SSRI resistant combat-related PTSD: a double-blind, placebo-controlled study. Am J Psychiatry 2003; 159: 1777-9.

75 Davidson JR, Connor KM, Hertzberg MA, Weisler RH, Wilson WH, Payne VM. Maintenance therapy with fluoxetine in posttraumatic stress disorder: a placebo-controlled discontinuation study. J Clin Psychopharmacol 2005; 25 : $166-9$.

76 Leucht S, Hierl S, Kissling W, Dold M, Davis JM. Putting the efficacy of psychiatric and general medicine medication into perspective: review of meta-analyses. Br J Psychiatry 2012; 200: 97-106.

77 World Health Organization. Guidelines for the Management of Conditions Specifically Related to Stress. WHO, 2013.

78 Australian Centre for Posttraumatic Mental Health. Australian Guidelines for the Treatment of Acute Stress Disorder and Posttraumatic Stress Disorder. ACPMH, 2013.

79 Jonas DE, Cusack K, Forneris CA, Wilkins TM, Sonis J, Middleton JC, et al. Psychological and Pharmacological Treatments for Adults With Posttraumatic Stress Disorder (PTSD). US Agency for Healthcare Research and Quality Comparative Effectiveness Review 92, 2013.

80 Watts BV, Schnurr PP, Mayo L, Young-Xu, Weeks WB, Friedman M. Metaanalysis of the efficacy of treatments for posttraumatic stress disorder. J Clin Psychiatry 2013; 74: e541-50.

81 Furukawa TA, Watanabe N, Omori IM, Montori VM, Guyatt GH. Association between unreported outcomes and effect size estimates in Cochrane meta-analyses. JAMA 2007; 297: 468-70.

82 Davidson JRT, Connor KM, Hertzberg MA, Weisler RH, Wilson WH, Payne VM. Maintenance therapy with fluoxetine in posttraumatic stress disorder: a placebo-controlled discontinuation study. J Clin Psychopharmacol 2005; 25 $166-9$ 